\title{
Outcome in placements for adoption or long term fostering
}

Joy S Holloway

\begin{abstract}
Objectives-To describe a five year cohort of children whose placements for adoption or long term (permanent) fostering were recommended by Newcastle upon Tyne Family Placement Panel and to determine the outcome of these placements.

Design-Retrospective total five year cohort study. Outcome data were extracted from records three to five years after placement.

Setting-Newcastle upon Tyne Social Services Adoption and Fostering Unit. Subjects-All 234 permanent family placements recommended by the Family Placement Panel from 1 January 1986 to 31 December 1990.

Main outcome measure-Disruption of the placement.

Results-A total of $20 \%$ of the placements had disrupted ( $2 \%$ of adoptive placements and $51 \%$ of long term fostering placements). Disruption was generally associated with increased age at placement. Disruption was not associated with special needs, the sex of the child, previous disruption, or being placed with siblings. Forty four per cent of children from disrupted placements returned to live with their birth families.

Conclusions-In view of the poor outcome for older children, there is a case for more preventative work and also for more support after placement.

(Arch Dis Child 1997;76:227-230)
\end{abstract}

Keywords: adoption; fostering; outcome; disruption.

Adoption has been a remarkable twentieth century phenomenon in Britain, with a rapid rise and fall in the number of infant adoptions between 1940 and 1980. ${ }^{1}$ The numbers peaked in 1968 with nearly 25000 adoptions, of whom over 12500 children were under 1 year old. In 1991, however, only 7000 children were adopted and only about 900 were infants. The role of medical advisers to adoption agencies has likewise altered. At one time they were primarily examining healthy newborn infants to ensure that they were 'fit for adoption'. Nowadays we assess many older children and children with disabilities or emotional and behavioural problems. Some children are placed for adoption and some are placed for long term fostering.

In 1975, in their classic study Children Who Wait ${ }^{2}$ Rowe and Lambert estimated that about 7000 children in care in the UK were waiting for family placements. Other studies reported that older or 'special needs' children could be successfully placed, ${ }^{34}$ so there was a move for 'permanence', seeking to place every child in a permanent substitute family. There followed many in depth studies of a small number of placements from pioneering voluntary agencies placing special needs children, ${ }^{56}$ as well as large scale national studies collecting less detailed information. ${ }^{78}$

This study demonstrates some of the difficulties in successfully placing older children. (These difficulties were explored further in a postal questionnaire sent to new carers and analysed in the companion paper. ${ }^{9}$ ) The study period spanned the introduction of the 1989 Children Act, which encourages maintaining children in their birth family if at all possible.

\section{Methods}

This is a retrospective five year cohort study of all the children whose placements for permanence (adoption or long term fostering) were recommended by the Family Placement Panel of Newcastle upon Tyne Social Services Department from 1 January 1986 to 31 December 1990. The city is in the northeast of the UK and has areas of considerable deprivation. Authorisation for access to adoption records was obtained from the Department of Health. Cohort placements were identified from the Family Placement Panel minutes. Only placements which actually took place were included. If a child had experienced several placements in this period, each placement was counted separately. Placements were included where short term foster parents were changing to become the child's permanent carers, but not where long term foster carers were changing to adoption. Placements with relatives were not included, nor were the two placements where the child was removed by the courts soon after placement.

Information about outcome was extracted from the card index systems in April 1994, 39-99 months after the panel met. Where necessary, files were drawn to check data. Disruption was defined as any termination of the placement, except leaving the family after the child's 18 th birthday or moving to independent living aged 16 plus.

Data were analysed using Epi-Info 5. The Yates's corrected $\chi^{2}$ test for proportions was used or a two tailed Fisher's exact test. A p value of less than 0.05 was taken as significant. Stratified analysis was used to deal with confounding factors. A total of 234 placements 
was identified which fitted these criteria and information was extracted for all of them.

DESCRIPTION OF COHORT

A total of 136 (58\%) of the children were boys; $98(42 \%)$ were girls. The ages at the panel meeting ranged from less than 1 month to 16 years. The ages were skewed to the left, with approximately a third (70) under 1 year, a third (82) aged 1-6 years, and a third (82) aged 7-16 years. Only $32(14 \%)$ of the children placed for permanence were traditional newborn infant placements.

Sixty five $(28 \%)$ of the 234 children were placed in a sibling group and of these $23(35 \%)$ were placed in groups of three or over. Thirty eight $(49 \%)$ of 78 children aged $2-7$ years were placed with siblings.

Eighty $(34 \%)$ placements were for long term fostering. A total of 129 (55\%) were placed for adoption. Another 25 (11\%) were placed for long term fostering with a view to adoption. (These were usually younger children who were not yet legally free to be placed for adoption, but adoption was expected to follow shortly.)

Fifteen $(6 \%)$ of the children had a previous disruption recorded. Three of these had had two disruptions. Twenty one (9\%) children had previously been cared for by these carers in a short term setting. These were generally older children.

Thirty six $(15 \%)$ children had special needs recorded in the minutes. This was not associated with age. In fact, seven of the 70 infants under 1 year old were identified as having special needs. Usually only major problems were recorded in the minutes-for example, Down's syndrome, brain damage, cystic fibrosis, or referral to a child psychiatry unit. Moderate behavioural problems and mild medical problems were not usually recorded.

The number of children placed fell from 54 in 1986 to 41 in 1990 , but this was not statistically significant. There was, however, a demonstrable trend for the number of infants under 1 year old to fall over time: 21 in 1986 and only five in $1990\left(\chi^{2}=4.647 ; p=0.0311\right)$. There was no change in the ratio of adoption to fostering over time, nor was there a change in the incidence of special needs recorded in the minutes.

The ages of the children at the time of the study ranged from 3 to 24 years. A total of 129 $(55 \%)$ children were of primary school age.

\section{Results}

Forty six $(20 \%)$ of the placements were disrupted during the study period (tables 1 and 2). Information was available for 33 children about where they went to live. Six $(13 \%)$ returned to short term foster care, seven $(15 \%)$ moved to residential care, $20(43 \%)$ returned to live with their birth family, and for $13(28 \%)$ the destination was not recorded. Fostering rather than adoption was strongly associated with disruption, as was the placement of older children.

When adjustment was made for age at placement, it was not possible to show that fostering
Table 1 Type of placement and disruption

\begin{tabular}{llcc}
\hline Type of placement & $\begin{array}{l}\text { No (\%) } \\
\text { disrupted }\end{array}$ & $\begin{array}{l}\text { Not } \\
\text { disrupted }\end{array}$ & Total \\
\hline $\begin{array}{l}\text { Long term fostering } \\
\text { Long term fostering with }\end{array}$ & $41(51)$ & 39 & 80 \\
$\quad$ a view to adoption & $2(8)$ & 23 & 25 \\
Adoption & $3(2)$ & 126 & 129 \\
Total & $46(20)$ & 188 & 234 \\
\hline
\end{tabular}

$\chi^{2}=77.2 ; \mathrm{p}=<0.0001(\mathrm{df}=2)$.

Table 2 Age of child at panel meeting and disruption

\begin{tabular}{|c|c|c|c|c|c|c|}
\hline & \multicolumn{5}{|c|}{ Age at panel meeting (years) } & \multirow[b]{2}{*}{ Total } \\
\hline & $0-3$ & $4-7$ & $8-11$ & $12-15$ & 16 & \\
\hline \multicolumn{7}{|l|}{ No $(\%)$} \\
\hline $\begin{array}{c}\text { disrupted } \\
\text { Not disrupted }\end{array}$ & $\begin{array}{l}2(2) \\
112\end{array}$ & $\begin{array}{l}4(9) \\
41\end{array}$ & $\begin{array}{l}22(65) \\
12\end{array}$ & $\begin{array}{l}18(55) \\
15\end{array}$ & $\begin{array}{l}0 \\
8\end{array}$ & $\begin{array}{r}46 \\
188\end{array}$ \\
\hline Total & 114 & 45 & 34 & 33 & 8 & 234 \\
\hline \multicolumn{7}{|c|}{$\chi^{2}=97.52 ; \mathrm{df}=4 ; \mathrm{p}=<0.0001$} \\
\hline \multicolumn{7}{|c|}{$\begin{array}{l}\text { Table } 3 \text { Age of child at panel meeting and type of } \\
\text { placement }\end{array}$} \\
\hline & & \multicolumn{4}{|c|}{$\begin{array}{l}\text { Age at panel meeting } \\
\text { (years) }\end{array}$} & \\
\hline & & & 1 & -6 & -16 & Total \\
\hline \multirow{2}{*}{\multicolumn{2}{|c|}{$\begin{array}{l}\text { Long term fostering } \\
\text { Fostering with a view to } \\
\text { adoption }\end{array}$}} & & 0 & 72 & 2 & 80 \\
\hline & & & 1 & 20 & 4 & 25 \\
\hline Adoption & & & 9 & 4 & 6 & 129 \\
\hline Total & & & 8 & 82 & 2 & 234 \\
\hline
\end{tabular}

$\chi^{2}=189.5 ; \mathrm{df}=4 ; \mathrm{p}=<0.0001$.

was associated with a higher rate of disruption (table 3). Also the sex of the child, being placed with siblings, and special needs recorded in the minutes were not associated with disruption (30/136 (22\%) boys disrupted $v$ 16/98 (16\%) girls; $16 / 65(25 \%)$ siblings disrupted $v 30 / 169$ (18\%) without siblings; $10 / 36(28 \%)$ with special needs disrupted $v 36 / 198$ (18\%) without special needs). Where carers had previously cared for the child there were more disruptions, but these children were older at placement $(9 / 21$ (43\%) 'previously cared for by this family' disrupted $v 37 / 213$ (17\%) 'not previously cared for'). Children with a history of disruption were not more likely to disrupt in this study (4/15 (27\%) with a previous disruption $v 42 / 219(19 \%)$ without a previous disruption).

Almost all the disruptions (96\%) occurred when the child was 9 years old or over (fig 1). Most $(22 \%)$ occurred in the first six months of placement or when the child had been in placement for $18-41$ months (65\%) (fig 2).

A total of $144(62 \%)$ of the 234 cohort children were adopted by April 1994. This is $94 \%$ of the 154 children placed for adoption or for long term fostering with a view to adoption. Ten of these children were not adopted. Five of these placements had disrupted and five were either waiting for court proceedings to be finalised or were continuing as long term foster placements through choice. The quickest adoption order was granted four months after the panel meeting. The longest took five years and eight months. Forty seven adoption orders 


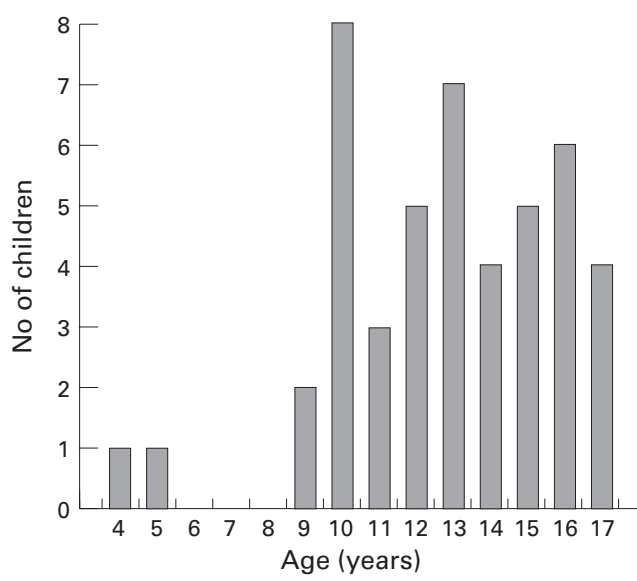

Figure 1 Age of child at time of disruption.

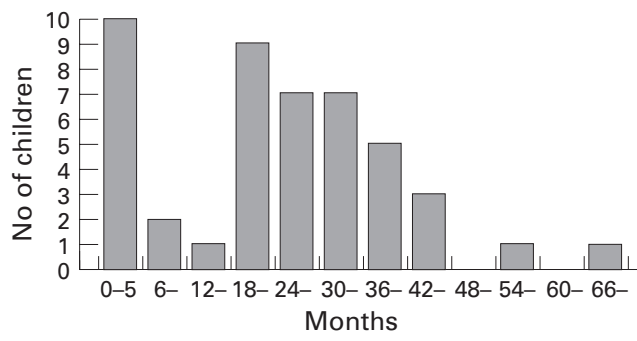

Figure 2 Time in placement until disruption.

were granted between seven and 12 months after the panel meeting. The median time was 14 months.

\section{Discussion}

Two Scottish studies have looked at the permanent placement of older and special needs children. ${ }^{10}{ }^{11} \mathrm{~A}$ total of 194 children placed in Lothian in 1982-5 had an overall disruption rate of $21 \%$ for children over 2 years old at placement and the rate rose rapidly for children over 8 years to $21-38 \%$. A study in Strathclyde of 117 permanent placements in 1983-4 also found the age at placement to be the best predictor of disruption and their disruption rate was $66 \%$ for children aged 12-16 years at placement. These results are roughly in line with this study in spite of the shorter follow up times in Scotland and differences in social work practice in time and area.

Disruption of the placement is a crude outcome measure. It shows that the placement did not work out as planned. In some instances disruption was seen as a positive step, as in other studies, ${ }^{812}$ but originally the plan at the panel meeting had been for the child to stay with that family until adulthood. Disruptions of 'permanent' placements are usually painful for both the child and the carer. The overall disruption rate was $20 \%$ and at least 20 of the 46 children whose placements disrupted returned to live with their birth families. This raises issues as to whether they should have left the birth family initially or whether the contact was handled appropriately.

As found in other studies, ${ }^{7}$ disruption was strongly associated with children being older when they were placed. In this study, however, children placed at primary school age had the highest disruption rate $(65 \%)$. This was even greater than the disruption rate for youngsters placed at $12-15$ years old ( $55 \%$ ), although the difference between these older age groups was not significant to $5 \%$.

The higher disruption rate for fostering placements appears to be due to the fact that the fostered children were older when placed. The age at placement was the most powerful factor for predicting disruption. The disruption rate was $56 \%$ for children placed for fostering aged 7 or over compared with only $1.6 \%$ of children under 7 placed for adoption. Sibling groups were not more likely to disrupt. This agrees with previous work. ${ }^{12}{ }^{13}$

Did this study include all the disruptions that are likely to happen, or will more disruptions occur in the future as the children grow older? The records were studied between 39 and 99 months after the children came to the panel. A total of $89 \%$ of the placements which disrupted in the study did so by 38 months. It seems likely that this study would have included most disruptions, but a few more may be expected in the future. One hundred and three $(44 \%)$ of the children were under 9 years old at the time of the study, so they still had their teenage years ahead of them, but by then they will have had 6-12 years in placement to settle and attach.

Did the study find all the disruptions which had occurred? The Adoption and Fostering Unit should have been aware of all the fostering placements which had disrupted as foster placements have statutory reviews. It is possible, however, that the unit was not notified of all adoptive placements which had disrupted after an adoption order, but these are expected to be infrequent events.

Almost all the disruptions occurred when the child was 9-16 years old. Youngsters of this age are able to apply considerable pressure when they want to move, especially if they wish to return to their birth family. This age range also covers adolescence, which causes turbulence in many intact families where young people do not have the added issues of separation from their birth parents.

In contrast with other studies, ${ }^{13}$ children who had previously been cared for by the same carers were more likely to disrupt than children placed with strangers. This result is most likely to be due to the fact that these children were an older group. Again, in this study, children with a previous history of disruption were not more likely to disrupt. This may be because, after a disruption, subsequent carers were chosen because they had more experience and perhaps they were given more support and more training, although the numbers were small (15).

Special needs as recorded in the minutes were not associated with disruption, but this definition of special needs probably underestimated behavioural problems. Sometimes medical problems and learning difficulties in young children help the bonding process and placements work out very well. ${ }^{7}$

How can the high disruption rates for older children be tackled? Given that entry into care is strongly associated with poverty and with 


\section{Key messages}

- Almost all children under 4 years of age placed for permanence remained with the new family

- Over half of the 'permanent' family placements of children over 7 years old disrupted

- More preventative work is needed to reduce the number of children needing placement

- Families taking older children need more support after placement

'broken families', ${ }^{14}$ primary prevention might be assisted by tackling the entrenched deprivation in some inner city areas and by encouraging the traditional family. Secondary prevention would be the provision of extra resources to support vulnerable families struggling to bring up children in difficult circumstances. If children are to be placed in substitute families, however, then they will need appropriate preparation and support after placement.

\section{Conclusions}

The study period spanned the introduction of the 1989 Children Act, which encouraged maintaining children in their birth family, if at all possible, although in these five years 234 children were placed for permanence in Newcastle upon Tyne. This study shows the great difference in disruption rates between adoptive placements of children under 7 and permanent fostering placements of older children. If it could be known that a particular child would eventually have to leave his or her birth family, then placement at an earlier age would thus be preferable as it would be less likely to disrupt. It is not easy, however, to foresee how a vulnerable birth family will respond to intensive support.

If placing children was a medical treatment, there would be much concern at a failure rate of $53 \%$ for children over 7 years old at placement. It must be remembered, however, that $47 \%$ of these placements continued and that some disrupted placements may have had a value for the child by providing the experience of good family life, if only for a few years. Nevertheless, disruption is normally negative. What can be done? This study suggests that there is a need for more preventative work and also that new families taking older children should be offered more support after placement as they are more at risk of disruption.

1 White Paper. Adoption the Future London: HMSO, 1993.

2 Rowe J, Lambert L. Children who wait. London: BAAF, 1975.

3 Tizard B. The effect of early institutional rearing on the development of eight year old children. Fournal of Child Psychology and Psychiatry 1978;19:99-118.

4 Wolkind S, Kosaruk A. 'Hard to place?' Children with medical or developmental problems. In: Wedge P, Thoburn I, eds. Finding families for 'hard to place' children. London: BAAF, 1986: 16-29.

5 Macaskill C. Against the odds. London: BAAF, 1985.

6 Thoburn J, Murdoch A, O'Brien A. Permanence in childcare. Oxford: Blackwell, 1987 .

7 Fratter J, Rowe J, Sapsford D, Thoburn J. Permanent family placement, a decade of experience. London: BAAF, 1991.

8 Rowe J, Hundleby M, Garnett L. Child care now. London: BAAF, 1985.

9 Holloway JS. Foster and adoptive mothers' assessment of permanent family placements. Arch Dis Child 1997;76: $231-5$.

10 Strathclyde Regional Council Social Work Department. Fostering and Adoption Disruption Research in Strathclyde Region - the permanent placements. The outcome of permanent family placements in two Scottish local authorities. Edinburgh: Scottish Office Central Research Unit Papers, 1991: 47-123.

11 Borland M, O'Hara G, Triseliotis J. Permanency, planning and disruption in the Lothian Region. The outcome of permanent family placements in two Scottish local authorities. Edinburgh: Scottish Office Central Research Unit Papers, 1991: 1-46.

12 Berridge D, Cleaver H. Foster home breakdown. Oxford: Blackwell, 1987.

13 Barth R, Berry M, Rogers Y, Goodfield R, Carson M. Predicting adoption disruption. Social Work 1988;33.3:227-33.

14 Bebbington A, Miles J. The background of children who enter local authority care. Br F Social Wk 1989;19:349-68.

Useful bibliography

Shaw M. A Bibliography of permanent family placement literature. London: BAAF, 1994

Social Services Inspectorate, Department of Health. Research which has a bearing on adoption or alternatives to adoption. London: Department of Health, 1993. 